\title{
Stage IIIB Hepatocellular Carcinoma AJCC v8
}

National Cancer Institute

\section{Source}

National Cancer Institute. Stage IIIB Hepatocellular Carcinoma A/CC v8. NCI Thesaurus. Code C134522.

Stage IIIB includes: T4, N0, M0. T4: Single tumor or multiple tumors of any size involving a major branch of the portal vein or hepatic vein, or tumor(s) with direct invasion of adjacent organs other than the gallbladder or with perforation of visceral peritoneum. N0: No regional lymph node metastasis. M0: No distant metastasis. (AJCC 8th ed.) 